\title{
Microwave Synthesis of Eco-friendly Nitrogen Doped Carbon Dots for the Corrosion Inhibition of Q235 Carbon Steel in $0.1 \mathrm{M} \mathrm{HCl}$
}

\author{
Mingjun Cui ${ }^{1, *}$, Yujie Qiang ${ }^{2}$, Wei Wang ${ }^{1}$, Haichao Zhao ${ }^{2}$, Siming Ren ${ }^{2, *}$ \\ ${ }^{1}$ Key Laboratory of Impact and Safety Engineering, Ministry of Education, School of Mechanical \\ Engineering and Mechanics, Ningbo University, Ningbo, 315211, China \\ ${ }^{2}$ Key Laboratory of Marine Materials and Related Technologies, Zhejiang Key Laboratory of Marine \\ Materials and Protective Technologies, Ningbo Institute of Materials Technology and Engineering, \\ Chinese Academy of Sciences, Ningbo, 315201, China \\ *E-mail: cuimingjun@ @bu.edu.cn, rensiming@ nimte.ac.cn
}

doi: $10.20964 / 2021.01 .47$

Received: 19 September 2020 / Accepted: 30 October 2020 / Published: 30 November 2020

In this work, nitrogen doped carbon dots (NCDs) were prepared with citric acid monohydrate $\left(\mathrm{CA} \cdot \mathrm{H}_{2} \mathrm{O}\right)$ and ethanolamine (EA) via microwave method. In combination with electrochemical techniques, weight loss and SEM, it is found that nitrogen doping in carbon dots effectively suppresses the corrosion of Q235 carbon steel in $\mathrm{HCl}$ solution owing to the presence of pyrrolic $\mathrm{N}$ in NCDs. Especially for NCDs (1:10), the optimum inhibition efficiency is about $89 \%$ after $1 \mathrm{~h}$ of immersion in $0.1 \mathrm{M} \mathrm{HCl}$ solution with $500 \mathrm{ppm}$ of concentration. By further calculation, the $\Delta G_{a d s}^{0}$ value for NCDs $(1: 10)$ is -26.65 $\mathrm{kJ} \cdot \mathrm{mol}^{-1}$, indicating the adsorption of NCDs on Q235 carbon steel surface involves both chemisorption and physisorption. In addition, NCDs still remain superior corrosion inhibition performance with the prolonged immersion time and ascending temperature.

Keywords: Microwave synthesis; NCDs; Corrosion inhibition; Q235 carbon steel.

\section{FULL TEXT}

(C) 2021 The Authors. Published by ESG (www.electrochemsci.org). This article is an open access article distributed under the terms and conditions of the Creative Commons Attribution license (http://creativecommons.org/licenses/by/4.0/). 